\title{
Television and Nutrition in Juvenile Detention Centers
}

\author{
Ed Wallace \\ Ithaca College
}

\begin{abstract}
Background: We sought to improve the ability of incarcerated juveniles to critically evaluate media food messages through an educational program that focused on nutrition. Methods: Surveys were administered to two groups of inmates of both sexes (seven to 16 years). The program consisted of forty-one 50 minute sessions (three times per week for 15 weeks) focusing on media and nutrition. Results: None of the participants identified accurate nutrition information before the intervention. After the program, the intervention group $(n=16)$ identified inconsistencies between nutrition labeling and media messages better than the controls $(n=17)$. Intervention inmates also expressed a greater interest in learning more about nutrition and had a better understanding of how diet is a factor in health. Conclusions: Health professionals can design health promotion programs that have a positive impact on the inmates' life while they are in custody, or after their release.
\end{abstract}

(C) 2005 Californian Journal of Health Promotion. All rights reserved.

Keywords: correctional facilities, media, nutrition, juvenile delinquents, television viewing

\section{Introduction}

Juveniles who are detained in correctional facilities should not be subjected to media messages promoting poor dietary habits that have long-term health consequences such as obesity, cardiovascular disease, or diabetes. Television viewing can have negative health effects on children, especially juveniles who are incarcerated (Committee on Public Education, 2001). There are approximately 102,000 inmates held in juvenile detention centers (Harrison \& Beck, 2004). Many of these inmates come from low-income communities (Mauer \& Coyle, 2004). If fact, Morton and Guthrie (1998) state that many low income children were less likely to know nutrition specifics such as diet and disease relationships or serving recommendations from the U.S. Department of Agriculture's "Food Pyramid.” This suggests that in order to lead healthy lives upon their release from correctional facilities, juveniles need to be targeted at an early age for dietary interventions.
The average youth watches an average of nearly three hours of television per day (Mares, 1998), and by the time they reach 70 years of age they will have spent the equivalent of seven to ten years watching television, including commercial messages that promote poor eating habits (Strasburger, 1993). Heavy viewing (more than three hours a day) has been associated with poor nutritional knowledge and incorrect information about the consumption of unhealthy foods (Atkin, 1976, 1980; Signorelli \& Lears, 1992). Recent studies have also demonstrated that as the hours of television watched increased, physical activity in adolescents decreased (Motl, McAuley, Birnbaum, \& Lytle, 2005), and body mass index increased (Kaur, Choi, Mayo, \& Harris, 2003). In fact, Cheng (2005) has described television viewing as a global risk factor for obesity.

In addition to physical inactivity, television commercials and program content have been demonstrated to have a negative influence on food preferences. A 1995 study 
determined that 91 percent of foods advertised during children's programming were high in fat, sugar, and/or salt -an issue of concern given that children and adolescents are greatly influenced by television messages (Taras \& Gage, 1995). Advertising, particularly television commercials, may play an important role in shaping the child's view of which foods are healthy (Wolfkin, 1977) and overeating (Halford, Gillespie, Brown, Pontin, \& Dovey, 2004).

Today, there is increased concern about the growing prevalence of overweight or obese adolescents, which many believe has reached epidemic proportions (Cheng, 2005). Television viewing and consumption of unhealthy foods are often cited as contributing to this epidemic (Atkin, 1976, 1980; Signorelli \& Lears, 1992). In spite of the high prevalence rates of overweight and obesity among adolescents, few primary prevention programs have been implemented or evaluated with high-risk juveniles. The "Turn Your Television Off" program, developed for this study, was a pilot program that utilized college students to help incarcerated adolescents learn about the fundamentals of good nutrition, and increase their ability to recognize sound versus unhealthful nutrition information in the media.

This study evaluates the short-term impact of the "Turn Your Television Off," a 15week intervention aimed at helping incarcerated adolescents and teens learn about health and nutrition. Objectives for participants were to increase knowledge of healthy foods, and to improve their ability to critically evaluate media messages. In order to conduct the study, participants of similar socio-economic status and ethnicity were recruited from two juvenile detention centers in New York State. These facilities hold young persons incarcerated by juvenile courts. Participants were racially homogeneous (98 percent Whites and two percent African Americans). The participants were almost equally split between males (46 percent) and females (54 percent), and the mean age for the intervention and control groups were 14 and 15 years respectively. The total capacity of these centers was 20 juveniles, which limited the size of our intervention and control groups.

\section{Methodology}

The "Turn Your Television Off" program is comprised of forty-one 50 minute sessions, facilitated three times a week by college students, at a New York juvenile detention facility. A 15-week upper-level course at Ithaca College provided the students with training by experts in nutrition education, criminal justice, health promotion, and other relevant topics. The students led the sessions and served as peer counselors to the inmates.

During the 15-week program, the participants completed activities that increased their awareness about healthy and unhealthy foods. A significant component in the program was teaching participants how to interpret media messages, especially television commercials. In order to better understand these commercial messages, the juveniles' video recorded and viewed a variety of food advertisements on television. Participants were then given packaged food products and asked to analyze the labels to determine if the commercials provided nutritional information that was consistent with the labeling. After analyzing both the advertisements and the labels, the inmates found that the commercial messages were inconsistent with the labels. As a result, they were encouraged to write letters to food distributors about the ingredients in their products and the inconsistency with the commercial messages. Following completion of the program inmates were rewarded a "Turn Your Television Off" certificate.

In order to evaluate the effectiveness of the intervention, participants were tested before the program (pre-test), and after 15 weeks (post-test). Test questions were drawn from 
the 2003 Youth Risk Behavior Surveillance System (YRBSS) instrument (see Brener et al., 2004). The items on the test consisted of questions that solicited feedback about nutrition, obesity, and body image. These components were evaluated on a five-point scale. A score of one indicated no or little knowledge about nutrition, and an inability to evaluate media messages. A score of five, by contrast, indicated the youth's ability to evaluate media message and rate them relative to healthy nutritional guidelines (similar to the food pyramid).

This study has a few limitations that must be addressed. First, the data were collected via self-report. Second, we used a small intervention $(\mathrm{n}=16)$ and control groups $(\mathrm{n}=$ 17 ), although this was the consequence of the correctional facility having less than 20 beds. Additional information, such as number of hours of television watched, may have enhanced our findings - but these were not collected. Despite these limitations this study suggests that a more decisive strategy is needed to educate juveniles about the negative influence of television ads and food choices that they see daily.

\section{Results}

A baseline survey assessed the participant's perceptions of accuracy in reports about nutrition, and their nutritional knowledge. A post intervention survey, conducted 15 weeks later, evaluated these same factors, and whether there was a short term difference. The results, presented in Table 1 , reveal that the pre-test to post-test gain for the intervention group was greater than the control group.

The initial mean for the intervention group was 1.8 of a possible five demonstrated that participants were not able to accurately identify nutrition information before the intervention. Post-test scores, by contrast, revealed that the intervention group had better nutritional knowledge. Moreover, the intervention group was significantly more likely to indicate their intent to increase fruit and vegetable intake and make other positive lifestyle changes. Inmates in the control group also indicated a desire to learn more about nutrition. In the post-test survey, participants were also more likely to report that diet is a factor in health. Last, participants in the intervention group also had a greater ability to critically evaluate media messages.

The control group, juveniles who were held in another juvenile facility, had initial scores that were slightly higher than the controls, but not significantly different than the intervention group. As the control group was slightly older than the intervention group (a mean of 15 years for the controls compared to 14 years for the intervention participants), this may have had an impact on their baseline nutritional knowledge. Over the fifteen weeks, however, their scores were unchanged. Consequently, these results reveal that the "Turn Your Television Off" program is a promising method of increasing nutritional knowledge in populations of juvenile offenders.

These data were evaluated using chi-square analyses, and while there was a substantial change between the two tests, it was not statistically significant. This finding may be a consequence of the size of the samples, and follow-up interventions should use a greater number of participants. Thus, while the study is not conclusive, it does have promising outcomes, and should be replicated. 
Table 1

Perceptions of Media Accuracy and Nutritional Knowledge: Intervention and Control Groups of Juvenile Detainees (Mean values)

\begin{tabular}{|c|c|c|c|c|c|c|}
\hline & \multicolumn{3}{|c|}{ Control Group (n=17) } & \multicolumn{3}{c|}{ Intervention group (n=16) } \\
\hline Measure & Pre & Post & $\begin{array}{c}\text { Change } \\
\text { (Pre-Post) }\end{array}$ & Pre & Post & $\begin{array}{c}\text { Change } \\
\text { (Pre-Post) }\end{array}$ \\
\hline Media Accuracy $^{1}$ & 2.00 & 2.00 & 0.00 & 1.60 & 4.00 & $+2.40^{2}$ \\
\hline Nutritional Knowledge & 2.00 & 2.00 & 0.00 & 2.00 & 2.00 & +2.20 \\
\hline
\end{tabular}

${ }^{1}$ Values ranged from 1 (little knowledge) to 5 (comprehensive knowledge)

${ }^{2}$ Changes were not significantly $(p \leq 0.05)$ different than intervention group

\section{Conclusions}

Juveniles are at high risk for a number of health-related problems including involvement in risky behaviors, unprotected sex, alcohol use, and illicit drug consumption (Ruddell \& Mays, 2004). Those who are placed in juvenile detention should be given the opportunity to learn about healthy lifestyles and making positive choices. This study reveals that health promotion interventions such as "Turn Your Television Off" may be successfully implemented within juvenile detention centers using college students to facilitate the program. Such low-cost early intervention programs for juveniles have the potential to promote positive long-term eating habits and reduce the prevalence of obesity, or other long-term consequences of poor diets. This approach may also encourage juveniles to maintain their healthy eating upon release. Such interventions might also have a positive impact on the participants as the college students may be positive role models for these delinquent youths.

Recent studies have demonstrated that television viewing, especially for those youths who are watching many hours per day, may lead to a number health problems (Cheng, 2005; Kaur et al., 2003; Motl et al., 2005). Moreover, a number of studies reveal that watching music videos with violent content (such as gangster rap) may also contribute to higher involvement in violence (see Johnson, Adams, Ashburn, \& Reed, 1995). Thus, some juvenile detention centers have removed all of their televisions altogether and have also reported that the prevalence of violent behaviors decreased (Will, Owens, \& Camp, 2001). While it is difficult to advocate for the removal of all televisions from every juvenile facility it seems consistent with health promotion to not only educate juvenile offenders about nutrition, but to reduce their exposure to television -- especially programs that promote violence -- whenever possible.

\section{References}

Atkin, C. K. (1976). Children's social learning from television advertising: Research evidence on observational modeling of product consumption. Advances in Consumer Research, 3, 513-519.

Atkin, C. K. (1980). Effects of television advertising on children. In E. L. Palmer \& A. Dorr (Eds.), Children and the faces of television: Teaching, violence, selling (pp. 287-305). New York, Academic Press.

Brener, N. D., Kann, L., Kinchen, S. A., Grunbaum, J. A., Whalen, L., Eaton, D., Hawkins, J., \& Ross, J. G. (2004). Methodology of the youth risk behavior surveillance system. Morbidity and Mortality Weekly Report, 53, 1-13. 
Cheng, T. O. (2005, in press). Television viewing as a global risk factor for childhood obesity. International Journal of Cardiology.

Committee on Public Education. (2001). American Academy of Pediatrics, Children, Adolescents, and Television. Pediatrics, 107, 423-426.

Gamble, M., \& Cotugna, N. (1999). A quarter century of TV food advertising targeted at children. American Journal of Health Behavior, 23, 261-267.

Halford, J. C. G., Gillespie, J., Brown, V., Pontin, E. E., \& Dovey, T. M. (2004). Effect of television advertisements for foods on food consumption in children. Appetite, 42, 221225.

Harrison, P. M., \& Beck, A. J. (2004). Prisoners in 2003. Washington, DC: Bureau of Justice Statistics.

Johnson, J. D., Adams, M. S., Ashburn, L., \& Reed, W. (1995). Differential gender effects of exposure to rap music on African American adolescents' acceptance of teen dating violence. Sex Roles: A Journal of Research, 33, 597-605.

Kaur, H., Choi, W. S., Mayo, M. S., \& Harris, K. J. (2003). Duration of television watching is associated with increased body mass index. Journal of Pediatrics, 143, 506-511.

Mares, M. L. (1998). Children's use of VCRs. Annual American Academy Political Social Science, 557, 120-131.

Mauer, M., \& Coyle, M. (2004). The social cost of America's race to incarcerate. Journal of Religion \& Spirituality in Social Work, 23, 7-25.

Motl, R. W., McAuley, E., Birnbaum, A. S., \& Lytle, L. A. (2005, in press). Naturally occurring changes in time spent watching television are inversely related to frequency of physical activity during early adolescence. Journal of Adolescence.

Morton, J. F., \& Guthrie, J. F. (1998). Changes in children's total fat intakes and their food group sources of fat, 1989-91 versus 1994-95: Implications for diet quality. Family Economics and Nutrition Review, 11, 45-57.

Ruddell, R., \& Mays, G. L. (2004). Risky lifestyles and unintentional firearms fatalities. Californian Journal of Health Promotion, 2, 49-64.

Signorelli, N., \& Lears, M. (1992). Television and children's conceptions of nutrition: Unhealthy Messages. Health Communication, 4, 245-257.

Strasburger, V. C. (1993). Children, adolescents, and the media: Five critical issues. Adolescent Medicine, 4, 479-493.

Taras, H., \& Gage, M. (1995). Advertised foods on children’s television. Archives of Pediatric Adolescent Medicine, 149, 649-652.

Will, J. A., Owens, C. E., \& Camp, H. (2001). TV or not tv? The impact of the removal of television on assaultive behavior in a juvenile detention center. Journal for Juvenile Justice and Detention Services, 16, 1-17.

Wolfkin, R. (1977). An analysis of programming and advertising. Introduction. In F. E. Barcus, (Ed.), Children’s television (pp. 20-27). New York: Praeger.

\section{Acknowledgements}

I thank the staff at the two New York State Juvenile Detention Centers, the participants in this study, and the students at Ithaca College for their help and guidance in conducting this study.

Author Information

Edward Wallace, Ph.D.

Ithaca College

E-Mail: ewallace@ithaca.edu 